\begin{tabular}{c} 
Volume and Issues Obtainable at Center for Sustainability Research and Consultancy \\
Responsible Education, Learning and Teaching in Emerging Economies \\
ISSN: 2708-4310 (E): 2708-4183 \\
Volume 1: No. 1, June 2019 \\
CSRᄃ \\
Journal homepage: www.publishing.globalcsrc.org/relate \\
\hline
\end{tabular}

\title{
Depression among Students with Congenital and Adventitious Vision Loss
}

\author{
${ }^{1}$ Faiza Jaleel, ${ }^{2}$ Ghulam Fatima, ${ }^{3}$ Dur e Nayab
}

${ }^{1}$ Lecturer, University of Education, Township Campus, Lahore: faizakhan208@ gmail.com

${ }^{2}$ Associate Professor, Institute of Education and Research, University of the Punjab, Lahore: fatima.ier@pu.edu.pk

${ }^{3}$ Phd Scholar, Institute of Education and Research, University of the Punjab, Lahore: durenayab18@yahoo.com

\begin{tabular}{l}
\multicolumn{1}{c}{ ARTICLE DETAILS } \\
\hline History \\
Revised format: May 2019 \\
Available Online: June 2019 \\
\hline Keywords \\
Depression, Students, \\
Congenital, Adventitious and \\
Visual Impairment
\end{tabular}

JEL Classification: P36, I21

\begin{abstract}
The key purpose of this study was to investigate the depression in students with congenital and adventitious vision loss. The purposive sampling technique was used to select sample. A sample of 81 students with visual impairment (51 with congenital and 30 with adventitious) was selected from different educational institutions of Punjab, Pakistan. An Instrument was developed and validated through expert opinion and piloting on 30 students. The value of Cronbach Alpha was found .88. Data was analyzed by using independent $t$ test and ANOVA on SPSS. Independent sample ttest was used to see the significant difference in depression of students with congenital and adventitious vision loss. Results of t-test showed high significant difference $\left(\mathrm{t}=-2.285^{*}\right)$ of depression between students with congenital and adventitious vision loss. Adventitiously Visually Impaired students (mean, 65.70) were more depressive than congenitally visually impaired (mean, 58.37). Results also showed no significant difference (.856) between male and female students with vision loss. But females had high mean of depression (63.31) than males (60.25), it showed females were more depressive than males. To know about the difference of depression among age groups, ANOVA was applied. It showed there is no significant difference $(\mathrm{F}, .113)$ of depression among three age groups. As result revealed adventitiously visually impaired are more depressive because of their late onset so they should be needed psychological counseling to cope their depression.
\end{abstract}

(C) 2019 The authors, under a Creative Commons AttributionNonCommercial 4.0

Corresponding author's email address: faizakhan208@gmail.com

Recommended citation: Jaleel, F., Fatima, G. \& Nayab, D. E., (2019). Depression among Students with Congenital and Adventitious Vision Loss. Responsible Education, Learning and Teaching in Emerging Economies, 1(1), 19-24

DOI: $10.26710 /$ relate.v1i1.1118

\section{Introduction}

Vision is an important part of life and life without vision is a challenge. This challenge need to be accepted in order to live healthy life. As vision loss is of two categories congenital and adventitious visual impairment. Students with adventitious visual impairment have different experiences of depression and 
other problems as compare to congenitally visually impaired students.

Eventually eye disorders that are not treatable can contribute in generating many problems and leads to avoidance in social situations and it results in social segregation and isolation, leading to health and physical decline. These situations need modifications and assistance in movements and physical arrangements (Ip, Leung, \& Mak, 2000).

Vision is one of the most precious senses that contribute a lot in our life. Without vision it is very difficult to live and performing different activities and recognizing different persons in gatherings, family and community. Most of the people not taken sense of vision seriously until the conditions leading to visual impairment. Vision impairment hinders many daily living activities. The consequence of visual impairment is intense and could result in many other conditions including unhappiness, worry or depression (Noran, Izzuna, Bulgiba, Mimiwati, \& Ayu, 2009).

Many problems are associated with vision loss as communication difficulties and social interactions and these variables make considerable association with depression. If person with visual impairment can successfully manage their social life with full support, their chances of experience depression could be lessen. But managing social support and intervention services for visually impaired person would be complicated. An intervention that need to be in practice for person with visual impairment to help them and demonstrate them that how they can do all of the physical and other interested activities with some modifications. Another help is to identify the transportation facilities for students with visual impairment which help them to enhance their access in social gatherings and participation in pleasurable activities and reduce their depression. Provision of some type of replacement activities could be helpful for decreasing depression in students with visual impairment (McDonnall, 2009).

Depression is a medical illness with many symptoms, including physical ones. Sadness is only a small part of depression. Some people with depression may not feel sadness at all, but be more irritable, or just lose interest in things they usually like to do. Depression interferes with your daily life and normal function. Don't ignore or try to hide the symptoms. It is not a character flaw, and you can't will it away (Buchanan, 2012). Some of the studies provide evidence that depression is the outcome of restricted activities and functional limitations (Benyamini, \& Lomranz, 2004).

Restriction and limitations in activities due to visual impairment leads to depression. It has been documented that facing difficulties in getting married, health problems, low quality relationships with others and unstable affiliation with peers are all considerable factors that stimulate depression in persons with visual impairment (Horowitz, Reinhardt, Boerner, \& Travis, 2003).

It was suggested in the study that depression was commonly found in the population with visual impairment. Impairment in visual and physical activities was found to be associated with signs of depression. Findings indicate that a person with visual and physical impairment is more at the risk of experiencing depression (Hayman, Kerse, La Grow, Wouldes, Robertson, \& Campbell, 2007).

It was investigated that there was strong connection between visual impairment and depression in adults who are socially at risk in Armenia. Early identification, detection and comprehensive screening of visual impairment could be very helpful in prevention of severe vision loss and managing other related psychological, physical and health problems (Giloyan, Harutyunyan, \& Petrosyan, 2015).

Visual impairment not only affects the individual experiencing visual impairment but also affect the family of that individual. Visual impairment causes the economic burden which leads to mental disturbance for the visually impaired individuals and their family members. It becomes the cause of depression in terms of financial burden on health systems. It is important to understand all of the finance related issues that rose due to blindness and low vision and connected with loss of interests, self- 
determination and excess rate of mortality (Köberlein, Beifus, Schaffert, \& Finger, 2013).

\section{Objectives of the Study}

The objectives of the study were to:

- Know about the depression in visually impaired students.

- Find out the effect of age, age on set on the depression of visually impaired students.

- Find out the difference of depression between male and female visually impaired students.

\section{Hypothesis}

- There was a significant difference of depression between congenitally and adventitiously visually impaired students.

- There was a significant difference of depression between male and female visually impaired students.

- There was significant difference of depression among three age ranges (15-20 years old, 21-25 years, 26-30 years).

\section{Methodology}

\subsection{Research Design}

To study the difference of depression between the students with congenital and adventitious vision loss, cross sectional descriptive research design was used. Depression level of male and female were also compared.

\subsection{Sample}

The population of this study consisted on students with congenital and adventitious vision loss at school, college and university level. The purposive sampling technique was used to select sample. A sample of 81 students (51 with congenital and 30 with adventitious) with visual impairment was selected from different educational institutions of Punjab province.

Both male and female visually impaired students were included in study. Age range of the students was from 15-30 years old and they studied in high school, College and university level. For the selection of sample, purposive sampling techniques were used.

\subsection{Instruments}

A five point rating scale, to measure the depression of students, was developed. It was consisted on 23 items. The items rating scale were based on relevant literature of depression. The first part of the questionnaire consisted of demographical information e.g. Names, Age, Class, Age on set, Severity level and institutes. The $2^{\text {nd }}$ part consisted of 23 questions for the subject. These questions were stated to measure depression.

The items were translated in Urdu for the convenience of school students. Results on these items were validated by expert opinion and reliability was also checked, it was found 79 Coefficient Alpha, that was much satisfactory.

\subsection{Data Collection}

The data was personally collected by researchers in a face to face meeting. The 23 item questionnaires were given to the students with congenital and adventitious vision loss. Researcher visited the schools, colleges and universities then got informed consent from principal and teachers of visually impaired students then administered questionnaire to students. 


\subsection{Data Analysis}

To measure the difference between depression of male and female and congenitally and adventitiously visually impaired t-test was applied. And ANOVA was also applied to measure the difference among three age ranges, 15-20 years 20-25 years and 25-30 years.

\subsection{Procedure}

The researchers reviewed the literature then set the objectives of the study and significance of the study. The researchers developed the questionnaire for students of visually impaired. Researchers visited the school for visually impaired children and got information through questionnaire from students. The data was personally collected by the researcher. After data collection it was tabulated and analyzed by SPSS and t-test. The results of the study were given in result chapter.

\section{Results}

The results on above given hypothesis are given below.

Table 1. The difference of depression between male and female Visually Impaired Students

\begin{tabular}{|l|l|l|l|l|}
\hline Gender & N & Mean & S.D & T \\
\hline Male & 59 & 60.25 & 15.17 & 0.856 \\
\cline { 1 - 4 } & & & & \\
\hline
\end{tabular}

Table 1 showed t value which showed no significant difference of depression between male and female visually impaired students. But the mean value of female is higher than the mean value of male. It revealed female were more depressive.

Table 2. Mean, standard deviation and t test of students with congenital and adventitious vision loss.

\begin{tabular}{|c|c|c|c|c|}
\hline Age Onset & $\mathrm{N}$ & Mean & S.D & $\mathrm{t}$ \\
\hline Congenital & 51 & 59.37 & 14.84 & $-2.285^{*}$ \\
\hline Adventitious & 30 & 65.7 & 12.21 & \\
\hline
\end{tabular}

$* 0.05$ sig.

Table no. 2 showed the significant difference of depression between the students with congenital and adventitious vision loss. Mean of students with acquired vision loss was higher than the congenital that means students with acquired / adventitious vision loss were more depressive than congenital.

Table 3: The difference of depression among students with different age ranges.

\begin{tabular}{|l|l|l|l|l|}
\hline Age & N & Mean & S.D & F \\
\hline $15-20$ years & 64 & 69.40 & 14.64 & 2.247 \\
\hline $20-25$ years & 9 & 68.66 & 10.03 & \\
$25-30$ years & 8 & 66.06 & 12.77 & \\
\hline
\end{tabular}


Table no. 3 showed the ANOVA result that was not significant. Depression was almost same in all three age groups. But mean value of students with age 15 to 20 was higher. They were more depressive than older age groups.

\section{Conclusion}

On the basis of research findings conclusion was drawn. There was no significant difference of depression between male and female visually impaired students. But the mean value showed female students with visual impairment were more depressive than male students with visual impairment. It was concluded that students with adventitious vision loss are more depressive than students with congenital vision loss. It can be said that accidental vision loss become the cause of depression. Further it was concluded that Depression is almost same in all three age groups. But mean value of students with age 15 to 20 is higher. They are more depressive than older.

\section{Discussion}

Early identification, detection and comprehensive screening of visual impairment could be very helpful in prevention of severe vision loss and managing other related psychological, physical and health problems. (Harutyunyan, \& Petrosyan, 2014). As visual impairment is the major cause of restriction and limitations in different daily routine activities, which may become the reason of depression in visually impaired students.

It was concluded that students with adventitious vision loss are more depressive than students with congenital vision loss. It can be said that accidental vision loss become the cause of depression. As sudden tragic conditions have some psychological effects. As students with congenital vision loss learn to live with situation of visual impairment from the time of their birth. But on the other hand students with acquired vision loss need some psychological support to cope up with situation of visual impairment.

\section{Recommendation}

On the basis of findings the following recommendations have been made:

- Psychological counseling services should be provided to the students with adventitious vision loss to cope their depression.

- Parents should be aware about different eye conditions of their children which are progressive in nature like Retinitis Pigmentosa.

- Teachers should provide proper counseling to the students with adventitious vision loss and help them to be independent with visual impairment.

- Early identification, detection and comprehensive screening should be provided to all students that help to manage their vision related psychological and health problems.

\section{References}

Benyamini, Y., \& Lomranz, J. (2004). The relationship of activity restriction and replacement with depressive symptoms among older adults. Psychology and aging, 19(2), 362.

Buchanan, J. L. (2012). Prevention of depression in the college student population: a review of the literature. Archives of Psychiatric Nursing, 26(1), 21-42.

Giloyan, A., Harutyunyan, T., \& Petrosyan, V. (2015). Visual impairment and depression among socially vulnerable older adults in Armenia. Aging \& mental health, 19(2), 175-181.

Horowitz, A., Reinhardt, J. P., Boerner, K., \& Travis, L. A. (2003). The influence of health, social support quality and rehabilitation on depression among disabled elders. Aging \& mental health, 7(5), 342350.

Hayman, K. J., Kerse, N. M., La Grow, S. J., Wouldes, T., Robertson, M. C., \& Campbell, A. J. (2007). Depression in older people: visual impairment and subjective ratings of health. Optometry and 
Vision Science, 84(11), 1024-1030.

Ip, S. P., Leung, Y. F., \& Mak, W. P. (2000). Depression in institutionalised older people with impaired vision. International journal of geriatric psychiatry, 15(12), 1120-1124.

Köberlein, J., Beifus, K., Schaffert, C., \& Finger, R. P. (2013). The economic burden of visual impairment and blindness: a systematic review. BMJ open, 3(11), e003471.

McDonnall, M. C. (2009). Risk factors for depression among older adults with dual sensory loss. Aging \& mental health, 13(4), 569-576.

Noran, N. H., Izzuna, M. G., Bulgiba, A. M., Mimiwati, Z., \& Ayu, S. M. (2009). Severity of visual impairment and depression among elderly Malaysians. Asia Pacific Journal of Public Health, 21(1), 43-50. 